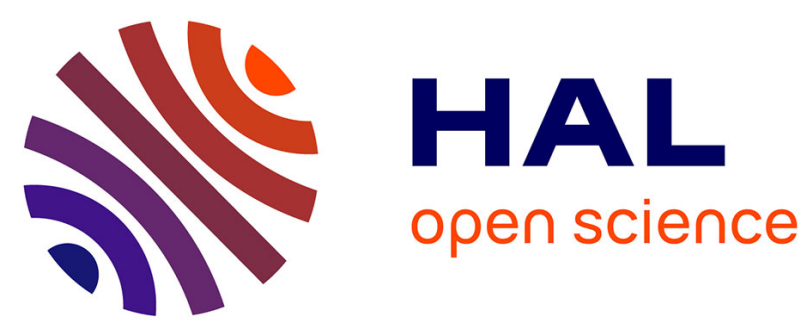

\title{
Cardanol-Based Epoxy Monomers for High Thermal Properties Thermosets
}

\author{
Anne-sophie Mora, Mélanie Decostanzi, Ghislain David, Sylvain Caillol
}

\section{To cite this version:}

Anne-sophie Mora, Mélanie Decostanzi, Ghislain David, Sylvain Caillol. Cardanol-Based Epoxy Monomers for High Thermal Properties Thermosets. European Journal of Lipid Science and Technology, 2019, 121 (8), pp.1800421-1800428. 10.1002/ejlt.201800421 . hal-02270139

\section{HAL Id: hal-02270139 \\ https://hal.science/hal-02270139}

Submitted on 15 May 2020

HAL is a multi-disciplinary open access archive for the deposit and dissemination of scientific research documents, whether they are published or not. The documents may come from teaching and research institutions in France or abroad, or from public or private research centers.
L'archive ouverte pluridisciplinaire HAL, est destinée au dépôt et à la diffusion de documents scientifiques de niveau recherche, publiés ou non, émanant des établissements d'enseignement et de recherche français ou étrangers, des laboratoires publics ou privés. 
*corresponding author:

4 Institut Charles Gerhardt, UMR 5253 - CNRS, Université de Montpellier, Ecole Nationale Supérieure de 5 Chimie de Montpellier, 240 Avenue Emile Jeanbrau, 34296 Montpellier, France

6 E-mail: $\underline{\text { sylvain.caillol@enscm.fr }}$

$8 \quad$ Keywords: cardanol; epoxide; cross-linking; anhydride; $T g$

Running Title: Cardanol-based epoxy monomers and polymers thereof

Abbreviations: DSC, differential scanning calorimetry, TGA, thermogravimetric analysis, DMA, dynamic mechanical analysis, NMR, nuclear magnetic resonance, ppm, parts per million, DGEBA, diglycidyl ether of bisphenol A, ECH, epichlorohydrin, CNSL, cashew nut shell liquid, CMR, Carcinogenic, Mutagenic and/or Reprotoxic, ECHA, European Chemicals Agency, mCPBA, meta-chloroperbenzoic acid, ECGE, epoxidized cardanol glycidyl ether, EMI, 2-Ethyl-4methylimidazole, MHHPA, hexahydro-4-methylphthalic anhydride.

\section{Abstract}

In this paper, epoxy-anhydride networks were synthesized from a new product of Cardolite ${ }^{\circledast}$ Corporation: the Cardolite GX-2551 epoxy monomer. Due to the complexity of the GX-2551 structure, a NMR study was performed first to characterize this new commercial product. This epoxy monomer was then reacted with an anhydride (MHHPA) to form polyepoxide thermosets. After curing, dynamic mechanical and thermal analyses have been performed for the different thermosets, and then the results were compared to each other.

\section{Practical applications}

The cardanol-derived epoxy monomer described in this contribution, ie: fully epoxidized molecular cardanol, is a new fully biobased monomer for further epoxy thermoset synthesis. The resulting polyepoxide networks exhibit much higher thermo-mechanical properties than previous cardanol-derived epoxy thermosets.

\section{Introduction}

Epoxy networks are one of the most common thermosets used in the industry due to their high thermal and mechanical properties inducing high performance applications such as engineering adhesives, paints, coatings, construction and composites. [1] The most widely used epoxy monomer in the epoxy network industry is diglycidyl ether of bisphenol A (DGEBA), which is prepared from hazardous substances: bisphenol A (BPA, a derivative of fossil resource) and epichlorohydrin (ECH). This preparation method is all the more concerning since BPA is carcinogenic and an endocrine disruptor. Therefore, the replacement of BPA in epoxy networks is of utmost importance. In an 
environmental context, concerns about the reduction of the carbon footprint is growing rapidly with the development of bio-based polymers. Many epoxy networks based on renewable resources have been developed recently from epoxidized natural oils such as soybean oil,[2,3] linseed oil[4] and castor oil.[5] However, all of these triglycerides exhibit similar structures with long flexible chains which provide low thermal or mechanical properties induced by a low crosslinking density and $T_{g}$. Recently, Webster et al. have described the sucrose soyate, a new biobased epoxy monomer which contains a sucrose backbone, inducing high rigidity and $T_{g}$ to the final thermosets.[6],[7] However, aromaticity is highly desired in epoxy networks in order to confer high thermal and mechanical properties to the final materials. Recently, some biobased aromatic epoxy networks have been obtained from tannins,[8] eugenol,[9,10] lignin,[11] and cardanol,[12-14]. Cardanol is a non-edible renewable resource with promising environmental potential due to its phenolic function and its long unsaturated aliphatic chain, which allows excellent thermal and mechanical properties. As a natural aromatic oil extracted from cashew nut shell liquid (CNSL), cardanol is mainly composed of anacardic acid and small quantities of cardanol, cardol, methylcardol and urushiol. The thermal decarboxylation of anacardic acid followed by a distillation allows one to obtain mostly cardanol (90\%), with a small quantity of cardol and methylcardol.[15] The long unsaturated aliphatic chain can be mono-, di- or triolefinic and each batch supplied by Cardolite Corporation is different in its composition. Generally, an average value of two unsaturations per molecule can be determined by ${ }^{1} \mathrm{H}$ NMR.

The first di-functional epoxy derived from cardanol which has been commercialized is the cardanol NC-514, resulting from phenolic condensation with epichlorohydrin. Cardanol NC-514 is supplied by Cardolite Corporation, which focuses on the supply of cardanol derivatives (Figure 1). Jaillet et al. have recently accurately described cardanol NC-514 and defined it as a mixture of polymer structures with closed and opened epoxy rings, induced by phenol addition and oligomerization.[16] Cardanol NC-541 is usually used as an epoxy prepolymer or flexibilizer in epoxy networks formulations,[17-21] and as flexibilizer in epoxy novolac coatings.[22,23] However, NC-514 is a phenolated cardanol and phenol is rarely used as a bio-based compound. Furthermore, it is highly toxic and classified as CMR (Carcinogenic, Mutagenic and/or Reprotoxic) by the ECHA (European Chemicals Agency).[24] Moreover, cardanol NC-514 has high viscosity due to its polymer structure, which limits its use.

In the current state of the art, the direct epoxidation of the unsaturations of cardanol have been studied for various applications. The direct epoxidation with perbenzoic acid has been described by Patel et al. in 1984.[25] The obtained di-functional cardanol was used as a reactive diluent for epoxy-anhydride thermosets. Then, Greco et al. worked on the epoxidation of the cardanol acetate unsaturation by meta-chloroperbenzoic acid (m-CPBA).[26] This methodology has also been carried out by Murray et al. on cardanol glycidyl ether in order to obtain a plasticizer. [27] With this method, most of the unsaturations were epoxidized but $m$-CPBA is known to generate lots of waste and to be shock-sensitive. This is the reason why the epoxidation of unsaturations with formic acid and hydrogen peroxide, considered as a "green" reagent, is now preferred. For instance, Suresh et al. have developed rigid polyurethane foams using this methodology to synthesize their intermediate compounds.[12] More recently, Sun et al. have synthesized the epoxidized cardanol glycidyl ether as an intermediate to obtain acrylated compounds in order to develop flexible bio-based acrylate coatings.[28] Unfortunately, in the literature, the obtained epoxidized cardanol 
glycidyl ether (ECGE) was only described by Murray et al. regardless of the complexity for both the initial and final mixtures. They considered that all the unsaturations were epoxidized.

In this context, Cardolite Corporation has developed a new fully bio-based epoxy monomer, derived from cardanol, in order to preserve the NC-514 properties while suppressing phenol from the synthesis. This new epoxy monomer, called Cardolite GX-2551 (Figure 1), is described as a low viscosity, low color, and theoretically difunctional epoxy monomer without phenol addition. It is prepared from the epoxidation of the phenol with glycerinderived epichlorohydrin and then by the direct epoxidation of the double bonds of the aliphatic chain.

Hence, the aim of this work is to describe and characterize the GX-2551 monomer supplied by Cardolite ${ }^{\circledR}$ Corporation, which has never been reported in the literature so far and used as an epoxy monomer in epoxy networks. Novel anhydride-epoxy thermosets based on cardanol GX-2551 was synthesized and both thermal and mechanical properties were compared to a thermoset based on cardanol NC-514 as reference.
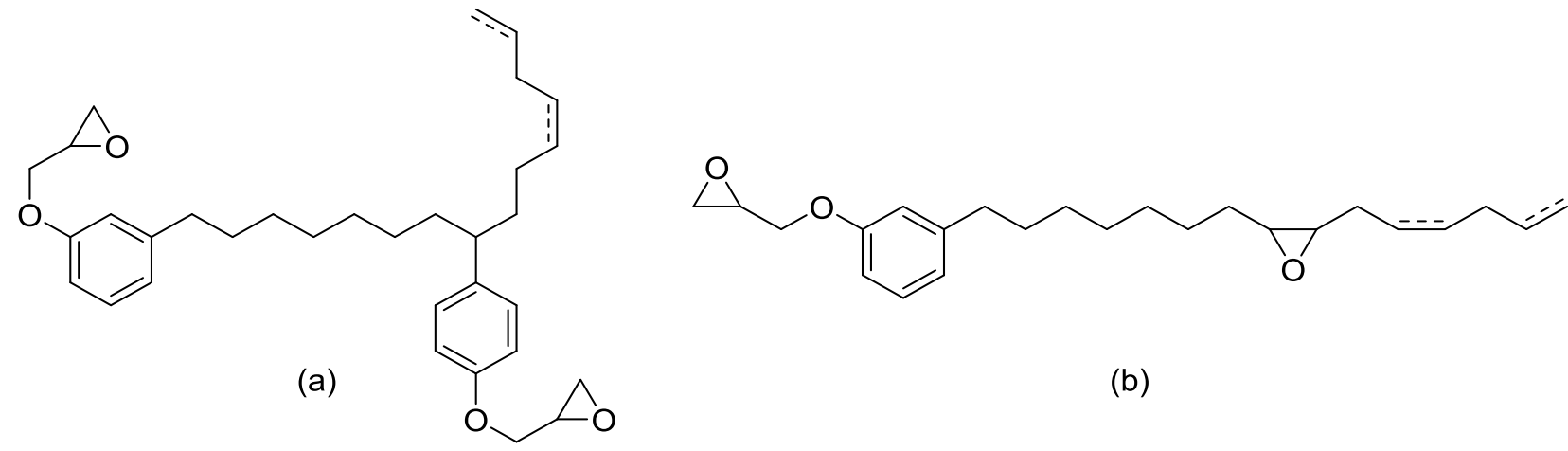

Figure 1: Theoretical structures of NC-514 (a) and GX-2551 (b)

\section{Experimental}

\section{Materials}

Epoxy monomers Cardolite GX-2551 and NC-514 were supplied from Cardolite ${ }^{\circledR}$ Corporation and used as received. Cardolite GX-2551 is described as a low viscosity, low color, di-functional epoxy monomer based on cashew nutshell liquid 165-200 g.eq ${ }^{-1}$ ). Cardolite NC-514 is described as a di-functional glycidyl ether epoxy monomer that, unlike other flexible monomers, exhibits the reactivity and chemical characteristics of a Bisphenol A type monomer (EEW = 350-500 g.eq ${ }^{-1}$ ). 2-Ethyl-4-methylimidazole (EMI), and hexahydro-4-methylphthalic anhydride (MHHPA) were purchased from Sigma-Aldrich and used without any further purification. Deuterated acetone was obtained from Sigma Aldrich for NMR study.

\section{Analytical techniques}

${ }^{1} \mathrm{H}$ and ${ }^{13} \mathrm{C}$ NMR analyses were recorded in deuterated acetone $\left(\left(\mathrm{CD}_{3}\right)_{2} \mathrm{CO}\right)$ using a $400 \mathrm{MHz}$ Bruker Aspect NMR spectrometer at a temperature of $23^{\circ} \mathrm{C}$. The chemical shifts were reported in parts per million (ppm) relative to tetramethylsilane. Spin multiplicity is shown by $\mathrm{s}=$ singlet, $\mathrm{d}=$ doublet, $\mathrm{t}=$ triplet, $\mathrm{m}=$ multiplet. 
Epoxy equivalent weight (EEW) is the amount of epoxy monomer in grams for one equivalent of reactive epoxy groups in moles. A range of EEW values were given by suppliers. More accurate EEW values were determined by $3{ }^{1} \mathrm{H} N M R$.

- EEW of NC-514 was determined using an internal standard (benzophenone). Known weights of epoxy and benzophenone were poured into an NMR tube and $500 \mu \mathrm{L}$ of deuterated acetone were added. EEW values were determined according to Equation (1).

Equation (1) $\quad E E W=\frac{\int P h C O P h * H_{\text {epoxy }}}{\int \text { epoxy } * H_{\text {PhCOPh }}} * \frac{m_{\text {epoxy }}}{m_{P h C O P h}} * M_{P h C O P h}$

where:

$\int_{\text {PhCoph: }} \quad$ integration of the benzophenone protons;

$\int_{\text {epoxy: }} \quad$ integration of the protons of the epoxy functions;

$H_{\text {epoxy: }} \quad$ number of protons of the epoxy functions;

$H_{\text {PhCoph: }} \quad$ number of protons of the benzophenone;

$m_{\text {epoxy: }} \quad$ weight of the epoxy product;

$m_{\text {PhCOPh: }} \quad$ weight of benzophenone;

$M_{\text {PhCOPh: }}$ molecular weight of benzophenone

11 - EEW of GX-2551 was determined without internal reference. In this case, it was necessary to deduct the signal of -

$12 \mathrm{CH}_{2}$ designated as $\mathrm{j}$ (Figure 3 ), which is overlapping with epoxy signals. To this end, the integration of the signal of $2 \mathrm{x}$

$13-\mathrm{CH}$ designated as $e$ is deducted according to Equation (2).

Equation (2) $\quad E E W=\frac{\int \text { internal epoxy }+\int \text { glycidyl epoxy }-\int(e)}{n_{\text {Function epoxy }}}$

where:
$\int_{i+i} *:$
integration of the internal epoxy corresponding to assigned signal;
$\int_{i}:$ integration of the internal epoxy corresponding to assigned signal;
$\int_{e}:$ number of protons of the internal double bonds;
$n_{\text {Function epoxy: }}$ number of epoxy functions;

Thermogravimetric Analyses (TGA) were performed with an F1-Libra analyzer (Netzsch) at a heating rate of 20 ${ }^{\circ} \mathrm{C}$. $\mathrm{min}^{-1}$ between 25 and $600{ }^{\circ} \mathrm{C}$. All experiments were run under a stream of nitrogen. Approximately 9-10 mg of sample was placed in an aluminum crucible and heated under nitrogen atmosphere $\left(20 \mathrm{~mL} \cdot \mathrm{min}^{-1}\right)$. The moisture and volatile content, the percentage of residue at $600{ }^{\circ} \mathrm{C}$, and the degradation temperature $\left(T_{d}\right)$ were determined.

Differential scanning calorimetry (DSC) measurements were carried out using a NETZSCH DSC200F3 calorimeter F3 calibrated with indium standard under nitrogen atmosphere. Approximately $10 \mathrm{mg}$ of each sample were placed in pierced aluminum pans. The thermal properties were recorded from $-50{ }^{\circ} \mathrm{C}$ to $150{ }^{\circ} \mathrm{C}$ at $20^{\circ} \mathrm{C} \cdot \mathrm{min}^{-1}$ for GX-2551-MHHPA materials and from $-100{ }^{\circ} \mathrm{C}$ to $150{ }^{\circ} \mathrm{C}$ at $20{ }^{\circ} \mathrm{C} \cdot \mathrm{min}^{-1}$ for NC-514-MHHPA materials. The glass transition temperature $\left(T_{g}\right)$ values were measured on the second heating ramp. 
Dynamic Mechanical Analyses (DMA) were carried out on Metravib DMA 25 with Dynatest 6.8 software. Uniaxial stretching of samples was performed while heating at a rate of $3{ }^{\circ} \mathrm{C} \cdot \mathrm{min}^{-1}$ from $T_{g}-80{ }^{\circ} \mathrm{C}$ to $T_{g}+100{ }^{\circ} \mathrm{C}$, keeping frequency at $1 \mathrm{~Hz}$ with a fixed strain $\left(10^{-5} \mathrm{~m}\right)$. In order to determine its elastic domain, a variable stress has been previously applied to the material at a fixed temperature $\left(>T_{g}+30^{\circ} \mathrm{C}\right)$. For the second test, the dynamic strain applied has been chosen on this elastic domain.

Cross-linking density: From rubber elasticity theory,[29] the uniaxial stretching was studied on the rubbery plateau at $\mathrm{T}=T_{\alpha}+50$, and at very small deformations. Under these hypotheses, the cross-linking density $\left(v^{\prime}\right)$, was obtained from Equation (3), where $E^{\prime}$ is the storage modulus, $\mathrm{R}$ is universal gas constant and $T_{\alpha}$ is the temperature, in $\mathrm{K}$, of the transition from vitreous to elastic domain of the material determined at the maximum of the $\tan \delta$ curve. Calculated values are given for information purposes only, and they can only be compared.

$$
\text { Equation (3) } \quad v^{\prime}=\frac{E_{a t T \alpha+50}^{\prime}}{3 R T_{\alpha+50}}
$$

Swelling indices (SI) were measured with three samples of around 15-30 mg each which were separately put in THF for $24 \mathrm{~h}$. The swelling index was calculated according to Equation (4), where $m_{1}$ is the mass of the material after swelling in THF and $m_{2}$ is the initial mass of the material.

$$
\text { Equation (4) } \quad S I=\frac{m_{1}-m_{2}}{m_{2}} \times 100
$$

Gel contents (GC) were measured after SI measurements. The three samples were dried in a ventilated oven at $70{ }^{\circ} \mathrm{C}$ for $24 \mathrm{~h}$. The gel content was calculated according to Equation (5), where $m_{3}$ is the mass of the material after drying and $m_{2}$ is the initial mass of the material.

$$
\text { Equation (5) } \quad G C=\frac{m_{3}}{m_{2}} \times 100
$$

\section{Synthesis of epoxy/anhydride thermosets}

Epoxy prepolymer (NC-514 or GX-2551) and MHHPA were mixed with a previously determined optimal molar ratio in the presence of EMI ( 2 mol\%). The reaction mixture was placed in a $50 \mathrm{~mL}$ vessel and homogenized by stirring using a vacuum mixer system for $5 \mathrm{~min}$. Mixtures were first cured at $110{ }^{\circ} \mathrm{C}$ for $8 \mathrm{~h}$, then at $130{ }^{\circ} \mathrm{C}$ for $2 \mathrm{~h}$ to synthesize the final thermosets. Both epoxy and methylhexahydrophthalic anhydride present a theoretical functionality of 2 . Therefore, for a theoretical molar ratio of 1:1 between anhydride and epoxy groups, the necessary amount of hardener for $100 \mathrm{~g}$ of epoxy prepolymer is calculated according to Equation (6):

Equation (6) $\quad m_{\text {anhydride }}=\frac{m_{\text {epoxy }} \times M_{\text {anhydride }}}{E E W}$ 
The optimal ratios of each system were experimentally determined to achieve the highest $T_{g}$. Equation (6) may be adjusted by multiplying the amount by the desired ratio of anhydride/epoxy to test various ratios ranging from $0.8 / 2.0$ to $2.0 / 2.0$. The higher $T_{g}$ were selected for the rest of the studies.

\section{Results and discussion}

\section{a. GX-2551 characterization}

The GX-2551 epoxy is a new cardanol derivative supplied by Cardolite ${ }^{\circledR}$ Corporation with an EEW ranging between 165 and $200{\mathrm{~g} . e q^{-1}}^{-}$. However, GX-2551 is a mixture of several possible functionalized compounds and its composition is not accurately known. The GX-2551 was epoxidized in two steps: first onto phenol by using epichlorohydrin, then onto unsaturations by using hydrogen peroxide (Figure 2). The phenol group was first functionalized by epichlorohydrin. During this step, an opened glycidyl product can be formed as a side-product. The amount of opened glycidyl groups was determined by using ${ }^{1} \mathrm{H}$ NMR (see Figure 3 and supporting information for COSY NMR), i.e. integrations of protons $h$ at $3.29 \mathrm{ppm}$ and $h 2$ at $4.07 \mathrm{ppm}$, corresponding to closed and opened glycidyl rings respectively. With a fixed value of 40 for aromatic protons ( 4 theoretically), a value of $9 \%$ of opened glycidyl was obtained. Thus, there are $9 \%$ of opened glycidyl and $91 \%$ of glycidyl groups. The internal unsaturations were then epoxidized by hydrogen peroxide, which is known to be selective to internal unsaturations. epoxidized cardanol was performed. .

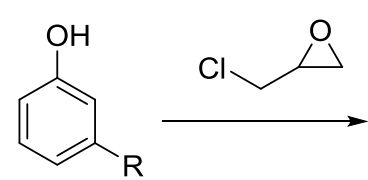

Cardanol<smiles>[R]c1cccc(OCC2CO2)c1</smiles>

Glycidyl Cardano
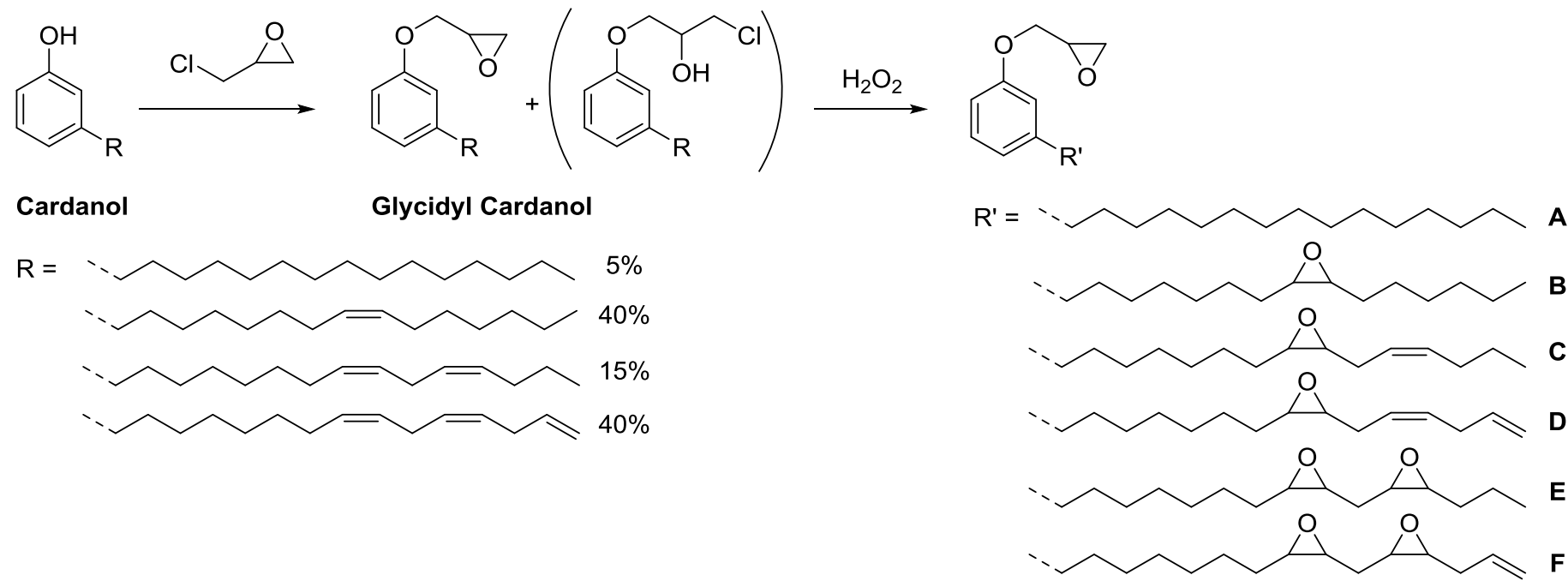

Figure 2: The different possibilities of structures present in GX-2551 composition.

In the ${ }^{1} \mathrm{H}$ NMR spectrum, the protons of the terminal double bond (designated as $d^{*}$ and $f^{*}$ ) of the diepoxidized chain can be observed at 5.96-5.86 ppm $\left(d^{*}\right)$ and at 5.21-5.06 ppm $\left(f^{*}\right)$, respectively. There are also lower intensity signals at 5.86-5.79 and 5.08-4.94 ppm, which correspond to terminal double bonds of the monoepoxidized chain ( $d$ and $f$ ) and to internal double bonds (designated as $e$ ) at $5.53 \mathrm{ppm}$. Moreover, the glycidyl ether group was assigned to five different signals : two doublets of doublets at 4.29 and $3.86 \mathrm{ppm}$ which correspond to the two non-equivalent protons $g\left({ }^{3} J=2.8 \mathrm{~Hz}\right.$ and $\left.{ }^{2} J=11.2 \mathrm{~Hz}\right)$ and $g^{\prime}\left({ }^{3} J=6.3 \mathrm{~Hz}\right.$ and $\left.{ }^{2} J=11.2 \mathrm{~Hz}\right)$ of the glycidyl, 
1 a multiplet signal of $-\mathrm{CH} h$ at $3.29 \mathrm{ppm}$ and non-equivalent protons $k\left({ }^{3} J=4.2 \mathrm{~Hz}\right.$ and $\left.{ }^{2} J=5.1 \mathrm{~Hz}\right)$ and $k^{\prime}\left({ }^{3} J=\right.$

$2 \quad 2.6 \mathrm{~Hz}$ and ${ }^{2} J=5.1 \mathrm{~Hz}$ ) at 2.82 and 2.70 which correspond to the $-\mathrm{CH}_{2}$ of the epoxy ring. The internal epoxy

3 groups are attributed to the confounded multiplet signals at 3.10-2.96 ppm for $-\mathrm{CH} i$ next to the unsaturated

4 bond and $-\mathrm{CH} i^{*}$ between the two internal epoxies, and then to the multiplet signal at 2.93-2.87 ppm for $-\mathrm{CH}$

$5 \quad i^{\prime}$ next to the aliphatic chain.

$6{ }^{1}$ H NMR of both mono- and di-epoxidized chains were compared to non-modified cardanol to assign the different

7 unsaturated double bonds (Figure 4). It should be noted that there were only traces of non-modified cardanol in the

8 GX-2551 mixture (insignificant presence of signals 2 and 3 corresponding to the aromatic protons of non-modified

9 cardanol), and no glycidyl cardanol without internal epoxy (no presence of signal $e^{\prime}$ corresponding to the protons of 10 its internal unsaturated double bonds).

GX-2551 Acetone
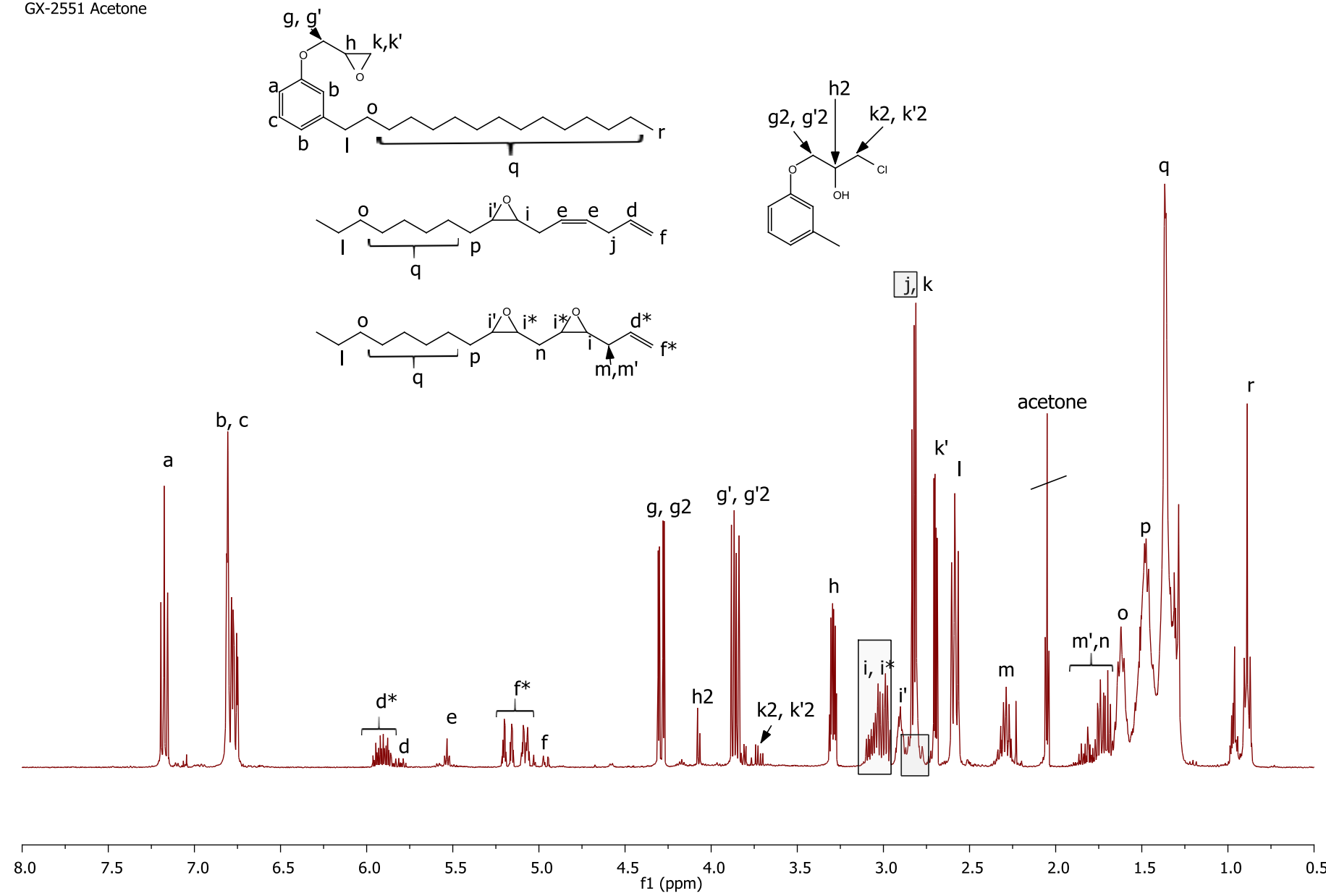

Figure 3: ${ }^{1} \mathrm{H}$ NMR of the GX-2551 recorded in deuterated acetone. 

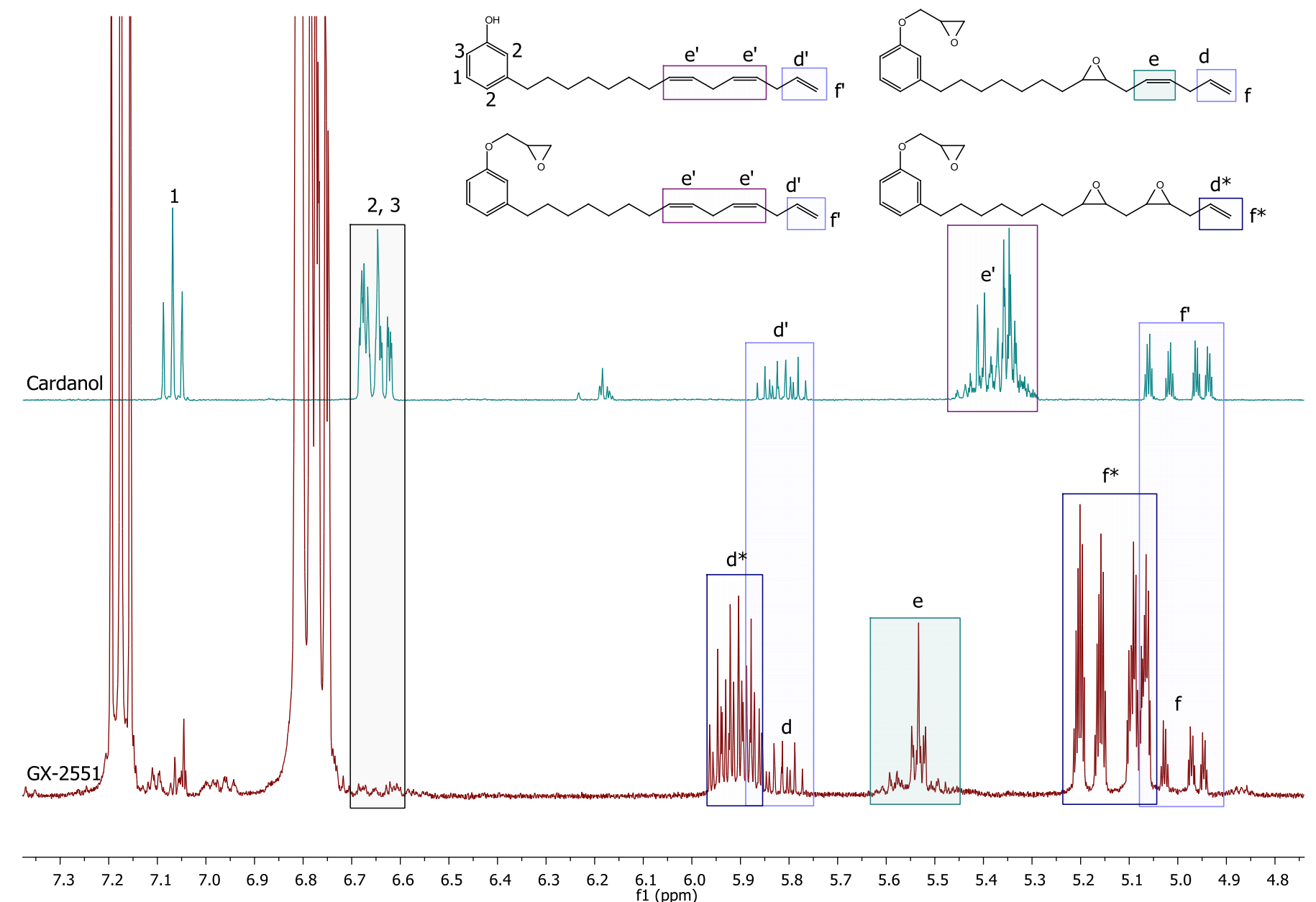

Figure 4: Comparison between ${ }^{1} \mathrm{H}$ NMR spectra of the non-modified cardanol (top) and the GX-2551 (bottom) recorded in deuterated acetone.

(1)

\section{(}

\section{b. Characteristics of monomer mixtures}

Once the GX-2551 was characterized, its characteristics were compared to those of the NC-514 (Table 1). The EEW were obtained by ${ }^{1} \mathrm{H}$ NMR analysis using an internal standard (cf. materials and methods) and compared to that of the supplier. The GX-2551 has a lower EEW than the NC-514, meaning that more epoxy functions are present in the GX-2551 monomer. This result was confirmed by the calculation of the epoxy functionality for each molecule. For this purpose, the integration of the GX-2551 monomer aromatic protons signal was fixed to 4 and the integrations of protons $h(=0.91)$ and $i, i^{\prime}$ and $i^{*}(=2.0)$ signals were then assessed. The functionality was determined to be 1.9. For the NC-514, the methodology of Jaillet et al. was used and a functionality of 1.3 was determined.[30] Table 1: Characteristics of GX-2551 and NC-514 epoxy mixture.

\begin{tabular}{|c|c|c|c|c|c|c|}
\hline & $\begin{array}{c}\text { EEW } \\
\text { from supplier } \\
\left(\text { g.eq }{ }^{-1}\right)\end{array}$ & $\begin{array}{c}\text { EEW } \\
\text { Exp. }^{\text {a }} \\
\left(\text { g.eq }^{-1} \text { ) }\right.\end{array}$ & $\begin{array}{c}\text { Number of } \\
\text { Epoxy } \\
\text { (per molecule) }\end{array}$ & $\begin{array}{c}\text { Viscosity } \\
\text { (mPa.s at } 25 \\
{ }^{\circ} \mathrm{C} \text { ) }\end{array}$ & $\begin{array}{l}T_{d 5 \%} \\
\left({ }^{\circ} \mathrm{C}\right)\end{array}$ & $\begin{array}{c}T_{g}^{\mathrm{b}} \\
\left({ }^{\circ} \mathrm{C}\right)\end{array}$ \\
\hline GX-2551 & $165-200$ & 163 & 1.9 & 85 & 212 & -64 \\
\hline NC-514 & $350-500$ & 490 & 1.3 & 15000 & 286 & -30 \\
\hline
\end{tabular}


${ }^{\mathrm{a}}$ by ${ }^{1} \mathrm{H}$ NMR. ${ }^{\mathrm{b}}$ mid value

Furthermore, the viscosity of NC-514 is more than 150 times higher than the GX-2551, which enables GX2551 to be more easily handled. Finally, their thermal properties were evaluated. The NC-514 has a higher thermal stability and a higher $T_{g}$ due to its higher aromaticity. However, the temperature at $5 \%$ weight loss $\left(T_{d 5 \%}\right)$ of the GX-2551 mixture is $212^{\circ} \mathrm{C}$, which allows for easy curing of the thermosets without degradation of the monomer. Knowing these characteristics, the properties of the cross-linked materials were evaluated.

\section{c. Epoxy-anhydride thermosets}

The lower reactivity of internal epoxies compared to terminal ones are well known in the literature, however, anhydrides are known to easily open these epoxy moieties.[31] This is the reason why the epoxies were cured with 4-methylcyclohexane-1,2-dicarboxylic anhydride (MHHPA), which is a common anhydride used in epoxyanhydride thermosets (Scheme 1).[7,32,33] MHHPA was also chosen for its liquid state at room temperature, as it allows for a homogeneous system, whereas most anhydrides are solids at room temperature and thus the mixing process is highly complicated. Furthermore, MHHPA will provide rigidity to the system due to its cycloaliphatic backbone.

In the case of the epoxy anhydride system, both moieties (epoxy and anhydride) have a functionality of 2, unlike conventional epoxy-amine systems whereas the epoxy only reacts once. In epoxy anhydride systems, the catalyst can activate the epoxy or the anhydride compound to form an alkoxy or a carboxylate function, which can then react with a new epoxy or anhydride species to form a polyester. ${ }^{4}$

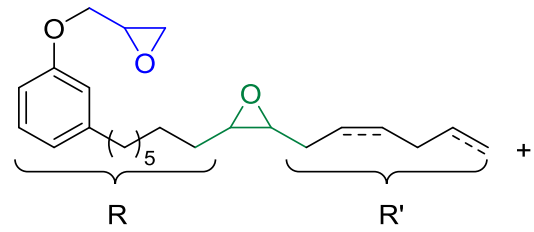

$\mathrm{R}$
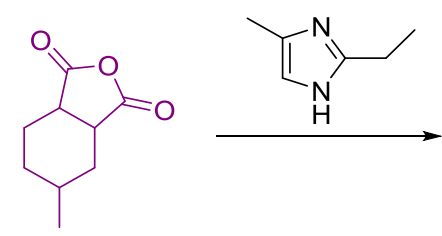

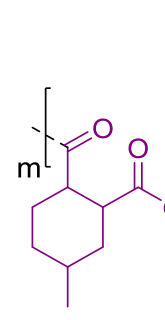<smiles>C/C=C/CCCCCCCCO</smiles>

Scheme 1: Reaction between the internal epoxy of GX-2551 and MHHPA in the presence of EMI.

The GX-2551 structure shows two epoxies with different reactivities: internal epoxy and glycidyl moiety. Internal epoxies are less reactive than terminal ones due to the steric hindrance. Hence, the nucleophilic substitution would be unfavored. Therefore, a stoichiometric study was carried out to determine the optimal epoxy-anhydride ratio of the two epoxy monomers. Each of them was mixed with MHHPA at different stoichiometric ratios according to Equation (6), and the $T_{g} \mathrm{~s}$ of each material were evaluated (results in Supporting Information). The optimal ratio is determined when the highest glass transition temperature is reached, indicating the highest level of cross-linking.

The theoretical optimal ratio should be 1 anhydride for 1 epoxy, however, the GX-2551 material has an optimal ratio of 1.0 epoxy for 1.2 anhydrides, whereas the NC-514-based material ratio is 1.0 epoxy for 1.0 anhydride (as shown in the Supporting Information). The difference between the theoretical and real optimal ratio 
Table 3: Characteristics of optimal epoxy anhydride thermosets. EEW value. materials are summarized in Table 3.

could be explained by the method used to determine the EEW (used in Equation (6)), which provides an approximate

Each epoxy mixture (GX-2551 or NC-514) and MHHPA in the presence of $2 \mathrm{~mol} \%$ of EMI was cured at $110^{\circ} \mathrm{C}$ during $8 \mathrm{~h}$, then $2 \mathrm{~h}$ at $130{ }^{\circ} \mathrm{C}$ using the previously determined ratio. Thermal and mechanical analyses of optimal

\begin{tabular}{|c|c|c|c|c|c|c|c|c|c|}
\hline & $\begin{array}{l}T_{d 5 \%} \\
\left({ }^{\circ} \mathrm{C}\right)\end{array}$ & $\begin{array}{c}\text { Char } \\
\text { yield }^{\mathrm{a}} \\
(\%)\end{array}$ & $\begin{array}{l}T_{g}^{\mathrm{b}} \\
\left({ }^{\circ} \mathrm{C}\right)\end{array}$ & $\begin{array}{c}T_{\alpha} \\
\left({ }^{\circ} \mathrm{C}\right)\end{array}$ & $\begin{array}{c}V \\
\left(\mathrm{~mol} / \mathrm{m}^{3}\right)\end{array}$ & $\begin{array}{l}\mathrm{E}_{\text {glassy }}^{\prime} \\
(\mathrm{Pa})\end{array}$ & $\begin{array}{c}\mathrm{E}_{\text {rubbery }}^{\prime} \\
(\mathrm{Pa})\end{array}$ & $\begin{array}{c}\text { SI } \\
(\%)\end{array}$ & $\begin{array}{l}\text { GC } \\
(\%)\end{array}$ \\
\hline GX-2551/MHHPA & 264 & 0 & 94 & 126 & 1160 & $1.3 .10^{9}$ & $1.3 .10^{7}$ & 86 & 100 \\
\hline NC-514/MHHPA & 316 & 2 & 42 & 69 & 542 & $1.4 .10^{9}$ & $5.3 .10^{6}$ & 125 & 93 \\
\hline
\end{tabular}

${ }^{\mathrm{a}}$ at $600{ }^{\circ} \mathrm{C} .{ }^{\mathrm{b}}$ mid value

DSC analyses were performed to determine the extent of reaction. No enthalpy was observed indicating full conversion. Furthermore, quantitative conversion was confirmed in the final networks with the swelling index (SI) and gel content (GC) analyses. The gel content measurement of the GX-2551/MHHPA thermoset was quantitative, indicating a completely crosslinked network. The NC-514/MHHPA thermoset exhibited a slightly lower gel content value due to non-functionalized cardanol chains as already observed in literature.[16] The swelling index gives insight to the amount of solvent that can penetrate into the network and thus the density of cross-linking. Swelling index measurements indicated that the NC-514 network is less cross-linked than the GX-2551 one. This is ascribed to the fact that THF can be easily inserted into the NC-514 network, resulting in a higher swelling index.

After complete curing, the temperature at $5 \%$ weight loss $\left(T_{d 5 \%}\right)$ of each network was measured by thermogravimetric analysis (TGA). Results showed that the GX-2551-based material had a lower thermal stability than the NC-514-based thermoset. These results could be explained by the presence of more aromatic moieties in NC-514 thus conferring higher thermal stability to the final network.[34] Furthermore, at $600{ }^{\circ} \mathrm{C}$, the materials were fully degraded, with char yields of nearly $0 \%$.

Bulk materials $(2.5 \times 0.5 \times 0.5 \mathrm{~cm})$ have been synthesized in order to assess the thermo-mechanical properties of each network by dynamic mechanical analysis (DMA). Figure 5 shows the storage modulus ( $E^{\prime}$ ) and $\tan \delta$ as a function of the temperature. In the glassy region, the two networks showed a similar storage modulus ( $E_{\text {glassy }}$ ) (around $1.10^{9} \mathrm{~Pa}$ ), demonstrating the high level of hardness and stiffness for thermosetting networks. In the rubbery domain, the storage modulus ( $\mathrm{E}_{\text {rubbery }}$ ) was proportional to the units between cross-linking nodes according to the theory of rubber-elasticity. $[35,36]$ The storage modulus ( $E_{\text {rubbery }}^{\prime}$ ) gives insight on the rigidity of a material and is linked to the cross-linking density $\left(v^{\prime}\right)$, thus they follow the same trend. Both values were higher for the GX-2551 
material meaning that this thermoset was more cross-linked and more rigid than that of NC-514. These results are in

2 agreement with that of SI and GC.

The alpha transition temperature $\left(T_{\alpha}\right)$ is a mechanical response of the $T_{g}$, and corresponds to the maximum 4 of the $\tan \delta$ curve. The $T_{\alpha}$ of the NC-514 thermoset is lower than that of the GX-2551 thermoset. The peaks of both $5 \tan \delta$ curves are narrow, suggesting that the materials are homogeneous. The EEW of GX-2551 is 163 g.eq $^{-1}$ and that 6 of the NC-514 is $490 \mathrm{~g} \cdot \mathrm{eq}^{-1}$. This means that for the same quantity of epoxy compound, there is more than twice the 7 anhydride content in the GX-2551 formulation. The anhydride possesses an aliphatic cycle conferring rigidity to the 8 system. Thus, the higher is the anhydride content, the higher is the $T_{g}$.

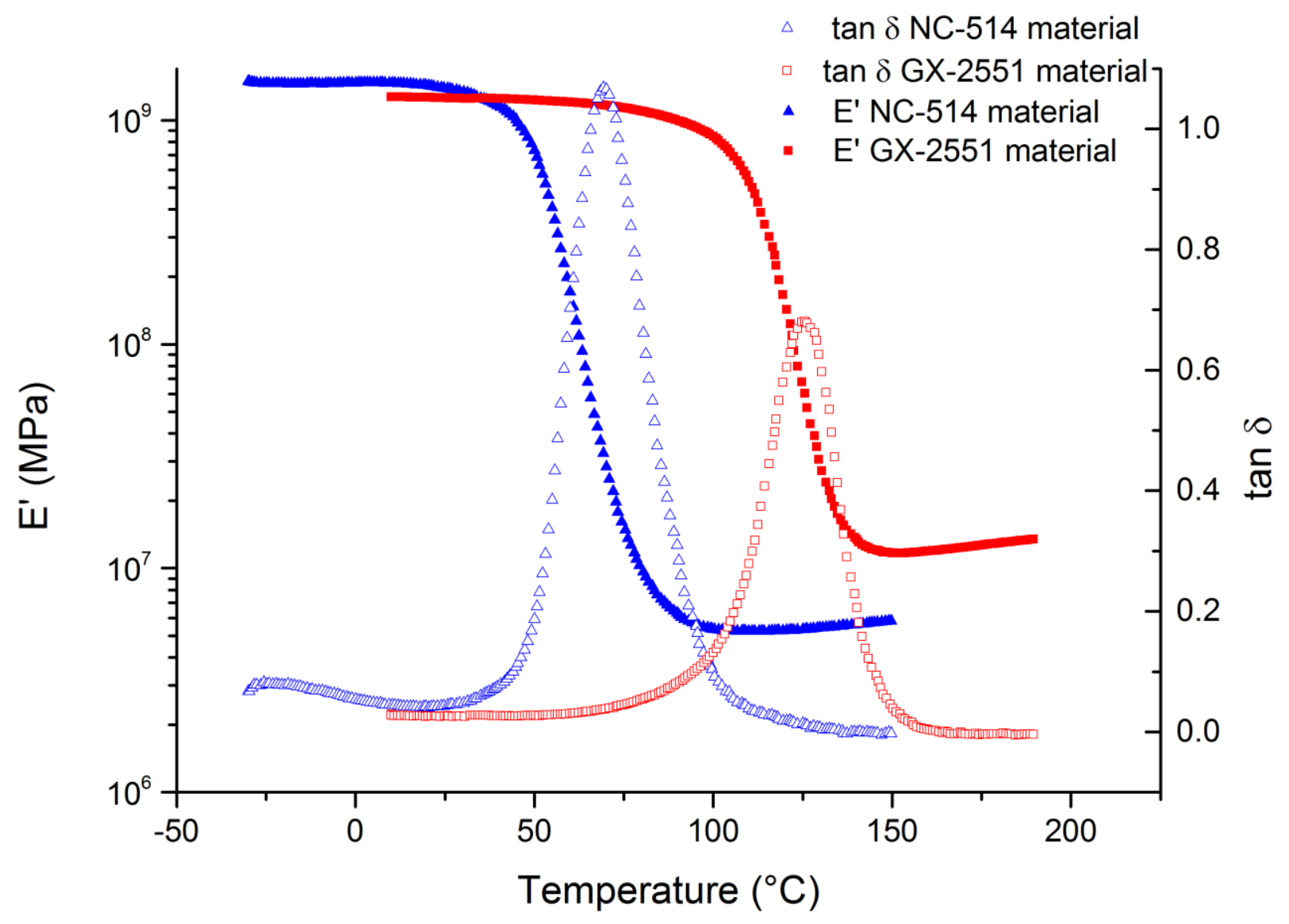

Figure 5: DMA curves of the NC-514 and GX-2551 materials.

\section{Conclusions}

The new GX-2551 epoxy has been accurately described using NMR spectroscopy and its thermal characteristics have been determined. The use of GX-2551 is of great interest because of its low viscosity and higher functionality compared to the NC-514. Moreover, the synthesis of GX-2551 does not require phenol, unlike that of NC-514.Biobased epoxy-anhydride thermosets were successfully synthesized from MHHPA with either GX-2551 or NC-514 (as 
1 networks. The GX-2551-based material showed high thermal and mechanical properties, with a glass transition

2 temperature value far higher than the one of the $\mathrm{NC}$-514-based material $\left(94{ }^{\circ} \mathrm{C}\right.$ vs $42{ }^{\circ} \mathrm{C}$ ). The $\alpha$ transition

3 temperatures follow the same trend $\left(126^{\circ} \mathrm{C}\right.$ vs $\left.69^{\circ} \mathrm{C}\right)$. Furthermore, the glassy storage modulus $\left(\mathrm{E}^{\prime}{ }_{\text {glassy }}\right)$ is very high 4 showing the high level of hardness and stiffness for these thermosets (around 1.10 $\mathrm{Pa}$ ). These properties allow GX52551 to be used for high performance material applications.

6

9 We sincerely thank Cardolite Corporation for providing a sample of the GX-2551.

11 The authors have declared no conflict of interest 


\section{References}

1. Kumar, S., Krishnan, S., Mohanty, S., and Nayak, S.K. (2018) Synthesis and characterization of petroleum and biobased epoxy resins: a review. Polym. Int., 67 (7), 815-839.

2. Altuna, F.I., Espósito, L.H., Ruseckaite, R.A., and Stefani, P.M. (2011) Thermal and mechanical properties of anhydride-cured epoxy resins with different contents of biobased epoxidized soybean oil. J. Appl. Polym. Sci., 120 (2), 789-798.

3. Sahoo, S.K., Mohanty, S., and Nayak, S.K. (2015) Toughened bio-based epoxy blend network modified with transesterified epoxidized soybean oil: synthesis and characterization. RSC Adv., 5 (18), 13674-13691.

4. Sahoo, S.K., Khandelwal, V., and Manik, G. (2018) Development of completely bio-based epoxy networks derived from epoxidized linseed and castor oil cured with citric acid. Polym. Adv. Technol., 29 (7), 2080-2090.

5. Sahoo, S.K., Khandelwal, V., and Manik, G. (2018) Renewable Approach To Synthesize Highly Toughened Bioepoxy from Castor Oil Derivative-Epoxy Methyl Ricinoleate and Cured with Biorenewable Phenalkamine. Ind. Eng. Chem. Res.

6. Pan, X., Sengupta, P., and Webster, D.C. (2011) Novel biobased epoxy compounds: epoxidized sucrose esters of fatty acids. Green Chem., 13 (4), 965.

7. Paramarta, A., and Webster, D.C. (2016) Bio-based high performance epoxy-anhydride thermosets for structural composites: The effect of composition variables. React. Funct. Polym., 105, 140-149.

8. Arbenz, A., and Avérous, L. (2015) Chemical modification of tannins to elaborate aromatic biobased macromolecular architectures. Green Chem., 17 (5), 2626-2646.

9. Wan, J., Zhao, J., Gan, B., Li, C., Molina-Aldareguia, J., Zhao, Y., Pan, Y.-T., and Wang, D.-Y. (2016) Ultrastiff Biobased Epoxy Resin with High $T_{\mathrm{g}}$ and Low Permittivity: From Synthesis to Properties. ACS Sustainable Chem. Eng., 4 (5), 2869-2880.

10. Wan, J., Gan, B., Li, C., Molina-Aldareguia, J., Li, Z., Wang, X., and Wang, D.-Y. (2015) A novel biobased epoxy resin with high mechanical stiffness and low flammability: synthesis, characterization and properties. J. Mater. Chem. A, 3 (43), 21907-21921.

11. Laurichesse, S., and Avérous, L. (2014) Chemical modification of lignins: Towards biobased polymers. Prog. Polym. Sci., 39 (7), 1266-1290.

12. Suresh, K.I. (2013) Rigid Polyurethane Foams from Cardanol: Synthesis, Structural Characterization, and Evaluation of Polyol and Foam Properties. ACS Sustainable Chem. Eng., 1 (2), 232-242.

13. Unnikrishnan, K.P., and Thachil, E.T. (2008) Synthesis and Characterization of Cardanol-Based Epoxy Systems. Des. Monomers Polym, 11 (6), 593-607.

14. Voirin, C., Caillol, S., Sadavarte, N.V., Tawade, B.V., Boutevin, B., and Wadgaonkar, P.P. (2014) Functionalization of cardanol: towards biobased polymers and additives. Polym. Chem., 5 (9), $3142-3162$.

15. Phani Kumar, P., Paramashivappa, R., Vithayathil, P.J., Subba Rao, P.V., and Srinivasa Rao, A. (2002) Process for Isolation of Cardanol from Technical Cashew ( Anacardium occidentale L.) 
Nut Shell Liquid. J. Agric. Food. Chem. $\quad, 50$ (16), 4705-4708.

16. Jaillet, F., Darroman, E., Ratsimihety, A., Auvergne, R., Boutevin, B., and Caillol, S. (2014) New biobased epoxy materials from cardanol. Eur. J. Lipid Sci. Technol., 116 (1), 63-73.

17. Xiong, Z., Ma, S., Fan, L., Tang, Z., Zhang, R., Na, H., and Zhu, J. (2014) Surface hydrophobic modification of starch with bio-based epoxy resins to fabricate high-performance polylactide composite materials. Compos. Sci. Technol., 94, 16-22.

18. Ng, F., Bonnet, L., David, G., and Caillol, S. (2017) Novel biobased and food contact epoxy coatings for glass toughening applications. Prog. Org. Coat. , 109, 1-8.

19. Nguyen, T.K.L., Livi, S., Soares, B.G., Barra, G.M.O., Gérard, J.-F., and Duchet-Rumeau, J. (2017) Development of Sustainable Thermosets from Cardanol-based Epoxy Prepolymer and Ionic Liquids. ACS Sustainable Chem. Eng., 5 (9), 8429-8438.

20. Eksik, O., Maiorana, A., Spinella, S., Krishnamurthy, A., Weiss, S., Gross, R.A., and Koratkar, N. (2016) Nanocomposites of a Cashew Nut Shell Derived Epoxy Resin and Graphene Platelets: From Flexible to Tough. ACS Sustainable Chem. Eng., 4 (3), 1715-1721.

21. Fouquet, T., Puchot, L., Verge, P., Bomfim, J.A.S., and Ruch, D. (2014) Exploration of cardanolbased phenolated and epoxidized resins by size exclusion chromatography and MALDI mass spectrometry. Anal. Chim. Acta, 843, 46-58.

22. Gour, R.S., Raut, K.G., and Badiger, M.V. (2017) Flexible epoxy novolac coatings: Use of cardanol-based flexibilizers. J. Appl. Polym. Sci., 134 (23).

23. Gour, R.S., Kodgire, V.V., and Badiger, M.V. (2016) Toughening of epoxy novolac resin using cardanol based flexibilizers. J. Appl. Polym. Sci., 133 (16).

24. Annex VI of Regulation (EC) No 1272/2008 (CLP Regulation), European Chemicals Agency, 2015.

25. Patel, M.B., Patel, R.G., and Patel, V.S. (1989) Effects of reactive diluent diepoxidized cardanol and epoxy fortifier on curing kinetics of epoxy resin. J. Therm. Anal., 35 (1), 47-57.

26. Greco, A., Brunetti, D., Renna, G., Mele, G., and Maffezzoli, A. (2010) Plasticizer for poly(vinyl chloride) from cardanol as a renewable resource material. Polym. Degrad. Stab., 95 (11), 21692174.

27. Chen, J., Liu, Z., Jiang, J., Nie, X., Zhou, Y., and Murray, R.E. (2015) A novel biobased plasticizer of epoxidized cardanol glycidyl ether: synthesis and application in soft poly(vinyl chloride) films. RSC Adv., 5 (69), 56171-56180.

28. Sung, J., and Sun, X.S. (2018) Cardanol modified fatty acids from camelina oils for flexible biobased acrylates coatings. Prog. Org. Coat., 123, 242-253.

29. Levita, G., Petris, S.D., Marchetti, A., and Lazzeri, A. (1991) Crosslink density and fracture toughness of epoxy resins. J Mater Sci, 26 (9), 2348-2352.

30. Jaillet, F., Darroman, E., Ratsimihety, A., Auvergne, R., Boutevin, B., and Caillol, S. (2014) New biobased epoxy materials from cardanol: New biobased epoxy materials from cardanol. Eur. $J$. Lipid Sci. Technol., 116 (1), 63-73.

31. Decostanzi, M., Lomège, J., Ecochard, Y., Mora, A.-S., Negrell, C., and Caillol, S. (2018) Fatty acid-based cross-linkable polymethacrylate coatings. Prog. Org. Coat., 124, 147-157. 
32. Liu, T., Hao, C., Zhang, S., Yang, X., Wang, L., Han, J., Li, Y., Xin, J., and Zhang, J. (2018) A Self-Healable High Glass Transition Temperature Bioepoxy Material Based on Vitrimer Chemistry. Macromolecules.

33. Yadav, S.K., Hu, F., La Scala, J.J., and Palmese, G.R. (2018) Toughening Anhydride-Cured Epoxy Resins Using Fatty Alkyl-Anhydride-Grafted Epoxidized Soybean Oil. ACS Omega, 3 (3), 2641-2651.

34. Dominguez-Rosado, E., Liggat, J.J., Snape, C.E., Eling, B., and Pichtel, J. (2002) Thermal degradation of urethane modified polyisocyanurate foams based on aliphatic and aromatic polyester polyol. Polym. Degrad. Stab., 78 (1), 1-5.

35. Kaji, M., Nakahara, K., and Endo, T. (1999) Synthesis of a bifunctional epoxy monomer containing biphenyl moiety and properties of its cured polymer with phenol novolac. J. Appl. Polym. Sci., 74 (3), 690-698.

36. Liu, W., Zhou, R., Goh, H.L.S., Huang, S., and Lu, X. (2014) From Waste to Functional Additive: Toughening Epoxy Resin with Lignin. ACS Appl. Mater. Interfaces , 6 (8), 5810-5817. 